\title{
Determination of Flavonoids (Catechins) by HPLC-ECD
}

\section{Hideharu Shintani ${ }^{\star}$}

Chuo University, School of Science, 1-13-27, Kasuga Bunkyo 112-0003 Tokyo, Japan

\section{Introduction}

Flavonoids are ubiquitous in the plant kingdom and are very efficient antioxidants. High-performance liquid chromatography (HPLC) with electrochemical detection (ECD) is a sensitive, simple and selective method for determination of flavonoids. Figure 1 shows typical HPLC chromatograms and the legend gives details of the method of preparation of HPLC samples of flavonoids (catechin) from the plasma of rats given green-tea extracts. The major flavonoids (catechins) in green-tea extracts are the four epicatechins: (-)-epicatechin, EC; (-)-epicatechin gallate, ECG; (-)-epigallocatechin, EGC; and (-)-epigallocatechin gallate, EGCG. They were separated on a ODS C18 reversed-phase column by isocratic elution with $85: 150.1 \%$ phosphoric acid-acetonitrile solution containing $0.1 \mathrm{mM}$ Na2EDTA [1].

\section{Protocol}

1. Add ethyl gallate $(0.1-50 \mu \mathrm{g} / \mathrm{mL}, 50 \mu \mathrm{L}$; internal standard) to plasma $(200 \mu \mathrm{L})$.

2. Add metaphosphoric acid solution $(30 \% \mathrm{w} / \mathrm{v}, 200 \mu \mathrm{L})$.

3. Mix for $1 \mathrm{~min}$.

4. Sonicate at $20 \mathrm{kHz}$ for $30 \mathrm{~s}$.

5. Leave to stand in an ice bath for $10 \mathrm{~min}$.

6. Centrifuge at $3000 \mathrm{rpm}$ for $10 \mathrm{~min}$.

7. Dilute with HPLC mobile phase and pass through $0.45-\mu \mathrm{m}$ filter.

8. Take $10-20 \mu \mathrm{L}$ of sample for analysis by HPLC with electrochemical detection (ECD)

HPLC was performed with a Shimadzu (Kyoto, Japan) LC-10AT

(A)

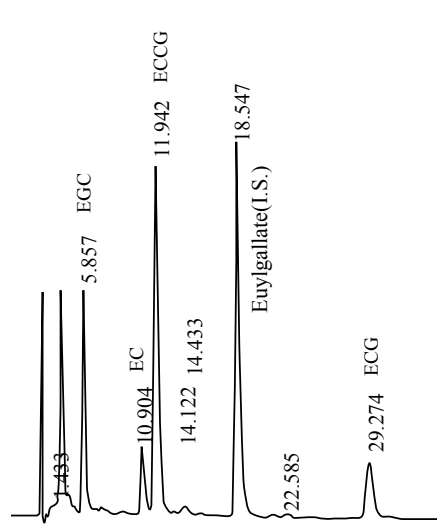

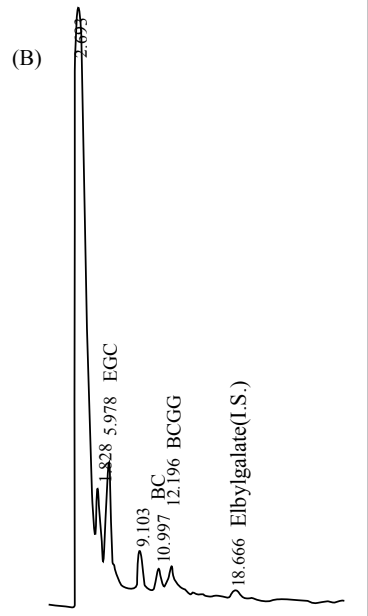

Figure 1: HPLC-ECD chromatogram of flavonoids (catechins). Sample A was prepared by adding a mixture of tea catechins $(50 \mathrm{mg} / \mathrm{ml})$ to rat plasma. Sample B was a plasma sample $(200 \mu \mathrm{L})$ prepared from blood obtained $1 \mathrm{~h}$ after oral administration of the catechin mixture $(100 \mathrm{mg} / \mathrm{kg})$. The catechin mixture contained EC $5.81 \%$, GC $1.44 \%$, ECG $12.51 \%$, EGC $17.57 \%$ and EGCG $53.90 \%$. pump and a Shiseido (Tokyo Japan) Nanospace Sl-1/2005 ECD with the applied voltage set at $600 \mathrm{mV}$. Compounds were separated on a 4.6 $\mathrm{mm}$ i.d. x $250 \mathrm{~mm}$ TSK gel ODS80Ts reversed-phase column (Tosoh, Tokyo, Japan) maintained at $30^{\circ} \mathrm{C}$ in a Shimadzu CT0-10 AC column oven. The mobile phase was 85:15 0.1 M phosphoric acid-acetonitrile containing $0.1 \mathrm{mM} \mathrm{Na2EDTA}$ at a flow rate of $1.0 \mathrm{~mL} / \mathrm{min}$. The limits of detection for epicatechins are approximately $1 \mathrm{ng} / \mathrm{mL}$ (signal-tonoise ratio, $\mathrm{S} / \mathrm{N}=3$ ) in plasma or bile.

\section{Discussion}

Aqueous solution of flavonoids (catechins) are readily oxidized and polymerized under alkaline conditions, but are fairly stable under acidic conditions. Oxidation is accelerated in the presence of metal ions such as $\mathrm{Fe}^{2+}, \mathrm{Fe}^{3+}$, and $\mathrm{Cu}^{2+}$. Plasma samples for HPLC analysis should be stored in the presence of an antioxidant and metal chelator. Epicatechins in rat or human plasma are relatively stable when mixed 1:50 (v/v) with VitaminC-EDTA solution (0.4 M NaH $\mathrm{PO}_{2}$ buffer containing $20 \%$ vitamin $\mathrm{C}$ and $0.1 \% \mathrm{Na}_{2} \mathrm{EDTA}, \mathrm{pH} 3.6$ ) and stored at $-80^{\circ} \mathrm{C}[2]$.

Free epicatechins are detected in plasma and bile 1-2 $\mathrm{h}$ after oral administration of tea catechin or green tea powder to rats or man [3-5] Epicatechins are also present in the conjugated form (e.g. glucuronide and sulfate) in plasma and bile, and hence, whole catechins can be detected after pretreatment with $\beta$-glucuronidase (Sigma G-7896) and sulfatase (Sigma S-9754) [2]. When EGCG, a major green tea catechin, is incubated with rat plasma or bile at $37^{\circ} \mathrm{C}$, three small peaks arising from three dimers can be detected in both fluids by following the disappearance of EGCG [5-9].

\section{References}

1. Umegaki K, Esashi T, Tezuka M, Ono A, Sano M, et al. (1996) Determination of tea catechins in food by HPLC with an electrochemical detector. J Food Hygiene Sci 37: 77-82.

2. Lee MJ, Wang ZY, Li H, Chen L, Sun Y, et al. (1995) Analysis of plasma and urinary tea polyphenols in human subjects. Cancer Epidemiol Biomarkers Prev 4: 393-399.

3. Unno T, Kondo K, Itakura H, Takeo T (1996) Analysis of (-)-epigallocatechin gallate in human serum obtained after ingesting green tea. Biosci Biotechnol Biochem 60: 2066-2068.

4. Okushio K, Matsumoto N, Kohri T, Suzuki M, Nanjo F, et al. (1996) Absorption of tea catechins into rat portal vein. Biol Pharm Bull 19: 326-329.

*Corresponding author: Hideharu Shintani, Chuo University, School of Science 1-13-27, Kasuga Bunkyo 112-0003 Tokyo, Japan, Tel: +81425922336; E-mail: shintani@mail.hinocatv.ne.jp

Received January 28, 2013; Accepted May 23, 2013; Published May 26, 2013

Citation: Shintani H (2013) Determination of Flavonoids (Catechins) by HPLCECD. Pharm Anal Acta 4: 238. doi:10.4172/2153-2435.1000238

Copyright: (c) 2013 Shintani H. This is an open-access article distributed unde the terms of the Creative Commons Attribution License, which permits unrestricted use, distribution, and reproduction in any medium, provided the original author and source are credited. 
5. Tomita I, Sano M, Sasaki K, Miyase T (1998) Tea catechin (EGCG) and its metabolites as bioantioxidants. ACS Symposium Series No. 701, Oxford Univ. Press 209-216.

6. Yoshino K, Suzuki M, Sasaki K, Miyase T, Sano M (1999) Formation of antioxidants from (-)-epigallocatechin gallate in mild alkaline fluids, such as authentic intestinal juice and mouse plasma. J Nutr Biochem 10: 223-229.

7. Novak I, Janeiro P, Seruga M, Oliveira-Brett AM (2008) Ultrasound extracted flavonoids from four varieties of Portuguese red grape skins determined by reverse-phase high-performance liquid chromatography with electrochemical detection. Anal Chim Acta 630: 107-115.

8. Kotani A, Hayashi Y, Matsuda R, Kusu F (2003) Prediction of measurement precision of apparatus using a chemometric tool in electrochemical detection of high-performance liquid chromatography. J Chromatogr A 986: 239-246.

9. Subagio A, Sari P, Morita N (2001) Simultaneous determination of (+)-catechin and (-)-epicatechin in cacao and its products by high-performance liquid chromatography with electrochemical detection. Phytochem Anal 12: 271-276. 